\title{
Consultancy project for the employer scenario of Google
}

\author{
Yuxi Yang* \\ Business and law faculty of Coventry University, The UK \\ Yangy48uni@163.com \\ ${ }^{*}$ Corresponding author
}

Keywords: Employer scenario, company's strategic position, Internet market analysis

\begin{abstract}
As core business is reaching out to the crowd, Google expands online as much as possible. Once it attracts users, it can use its technology to maximize profitability opportunities. This paper mainly analyses the strategic development approaches of Google which has been quite important for us to learn the way to react to the various business challenges with the flexible development strategies.
\end{abstract}

\section{Introduction}

This paper mainly analyses the strategic development approaches of Google, which has been quite important for us to learn the way to react to the various business challenges with the flexible development strategies. There will be three parts covered in this paper. The first will be the analysis of the company strategic position. Then, it comes to the analysis of the recommendations to address the issues identified by the relative evidence-based examples to explain the resolution strategies. The last one will be a brief reflection of what has been learned in this class.

\section{Analysis of the company's strategic position}

This part explores the three pillars of Google's strategy so that it can sell more ads for greater profitability. First, Google increases its coverage to remove barriers to its advertising; then, it expands its popularity, provides services to users, and creates more opportunities for advertising. Finally, it taps user data to grasp the best opportunities for users. Understanding and positioning are very effective. Google has implemented this strategy well. It ranked 92nd in the Fortune 500 in 2011 and the company has a valuation of nearly US\$200 billion. Last year, its tax contribution exceeded 29 billion. If calculated in terms of GDP, Google gets the equivalent of the GDP than either Cyprus or Bahrain. Although almost all the services it provides to users are free, Google’s net profit was \$8.6 billion in 2010 due to its digital business model $27 \%$ is a healthy profit margin [6].

Both operating systems are open source and can be used by anyone to access, develop and build derivatives [3]. Google provides an operating system such as Android for free because its goal is to commercialize the equipment that the system will run. If the restrictions imposed by the operators artificially increase the cost of network access, this is not a good thing for Google's business [4]. Services and subsidies will attract more eyeballs for Google. The reduction in service prices (nearly to zero) has indirectly promoted Google's core product demand, namely advertising. When many people access the Internet through the device, Google's second goal is to extend it to the user's Internet journey. In short, Google wants to become as many use cases as on the Internet to target user ads.

Google offers dozens of different services and as many tasks as possible to become the targets considered when users communicate or seek information. If the user wants to send an email, there is Gmail. Want to chat, Google Talk and Google Voice. Want directions? You can use Google Map or Google earth. YouTube allows users to post their own videos and share pictures via Picasa [3]. 
Google Apps (like "Google Docs") lets you work with your colleagues in a business environment. If you want to keep in touch with your friends, there is Google+. The list goes on. In most of these services, Google has an advertising business, which is not obvious, but it is always guaranteed to be visible to users [4]. Google does not do all the work that can touch users. Google provides infrastructure for others so that they can display ads. In this way, 30\% of its advertising revenue is obtained. Third parties can use the AdSense platform to display ads (and share profits) on their websites. There are similar platforms on mobile platforms [6]. Despite some competition, Google is still the main advertising provider on the Android Market. In fact, most Android developers derive their revenue from advertising rather than direct payments. Android Market's total number of paid applications are the lowest in all App markets. Finally, after clearing obstacles and expanding, Google's goal of attracting the most eyeballs has been achieved [7]. It increases the value of advertising by data mining users' behavior. By understanding which users are connecting ads at a certain moment, this user is provided relevant targeted ad serving. This increases the likelihood of the user clicking on an ad, combined with a fill-in rate and a click-through rate (CTR), to obtain the probability that the user will eventually purchase the ad product to generate value for the advertiser [4].

In its early days, Google completely changed the advertising industry in this way. Prior to this, the advertisement was broadcast to many users and hoped to be interested in it. Any targeted positioning is best, for example, advertisers can choose to print directly in the target magazine. When Google Search (its flagship product) comes out, suddenly you can locate users conveniently and near-perfectly through the content they search for [2]. This greatly improves the return on advertising. Typing a search has been just one of the ways Google uses to find out what content a user is interested in. Many insiders also confirmed that the Android operating system is used to collect user information [6].

\section{Recommendations to address the issues identified}

Google is now faced with two transitional periods. The mobile-phone network era, and how to achieve a perfect transition [3]. The US "Fortune" magazine recently conducted an interview with Google CEO Eric Schmidt. Eric Schmidt talked in an interview about how Google is facing the internal challenges it faces. Schmidt believes that at present, Google will focus on a lot of non-core business, which is not good for Google's long-term development, Schmidt is very worried about this.

Google believes that an open platform is easier to achieve rapid expansion. In the early days, Google often placed links to other search engines, at the bottom of the page. If users are not satisfied with Google's search results, they can easily try other competitors' websites. Similarly, Google has turned Android into an open platform. As a result, Android has seen explosive growth and rapid expansion in the fragmented mobile operating system market. Why is the open platform easier to achieve rapid expansion? First, opening is the exchange of scale and innovation at the expense of control. Opening can not only absorb creativity, but also reduce costs. Secondly, openness can make tens of thousands of people use it for you. Netflix was unable to improve the calculation method of the movie recommendation index. It launched a competition by opening user rating data to the outside world [2]. The result is that it quickly passes the wisdom of contestants. Found a solution. Third, openness allows users to enjoy freedom, and it is better to retain users than to confine consumers. Because if users can easily choose to unsubscribe from your service, you must work hard and make them willing to stay. If products and services have a significant competitive advantage and are in fast-growing emerging markets, then you can also build closed systems. Otherwise, choose to open it.

Many corporate leaders pay special attention to competitors, but Google does not think so. It takes a lot of time to focus on competitors and this approach will allow companies to fall into the mediocre [1]. If you focus on your competitors, you will never achieve true innovation because true innovation comes from user-based technical insights. Google's task is to think about things that ordinary people 
have yet to think of but that need to be considered, rather than what the competitors have already done. Focusing on the competitor's focus on the company can easily lead to blindly follow or tit-for-tat, thus ignoring the creation of more advantageous products or services. In other words, keeping a close eye on competitors means that you pay more attention to the way or means of serving users than the user needs themselves. Competing closely with competitors is the benchmarking company. The benchmarking has long been commonplace for Chinese companies, and it is very valuable for early Chinese companies to benchmark advanced international companies. For example, Vanke's bid for Pardi made Vanke focus on residential development and become a leading company in real estate in China [1]. The key to the success of this benchmarking is that the two are benchmarking and imitation of different historical stages of development in different markets in the same industry. However, it is obvious that the results of benchmarking tend to be convergent. If the subject of the bid is the same market company, it may be possible to make detours through benchmarking, but it is impossible to surpass the opponent.

\section{Evidence informed implementation strategy}

All other units (from the investment department (GV, Google Capital) to the X department) now belong directly to Alphabet. But we will refer to it in a unified manner using "Google," whether it now belongs to Google or Google before Alphabet. In the second quarter of 2016, the company's top-line and bottom-line growth exceeded the analysis's expectations (Chrome, Android, etc.). Mainly driven by Google's core advertising business, Alphabet's quarterly revenue jumped by $21 \%$ to US $\$ 21$. 5 billion, and profits increased by $24 \%$, exceeding market estimates [3]. This strong momentum is driven by a successful transition to mobile platforms, including new mobile ad formats and better performance evaluations. The so-called technical insight refers to the use of innovative methods to apply technology or design to achieve a significant reduction in production costs or a significant increase in product features and usability. Almost all of Google's successful products are based on solid technical insights. For example, the insight behind Google's most profitable advertising engine, AdWords, is that when ranking advertisements, the value of advertising information to users should be used as a standard, rather than looking at how much advertisers are willing to pay for advertisements. This seems to be something we are familiar with. Search engines have different business logic. Another example is the technical insight behind Google's open source browser, Chrome, that as the site becomes more sophisticated and powerful, the browser should also accelerate, which seems to be consistent with Fu Sheng's philosophy of doing Cheetah. So and so on.

In the 1990s, Google focused on one thing: to do a good job of search, and to continuously improve the quality of search engine services through speed, accuracy, ease of use, comprehensiveness, and freshness. At that time, Google was not the most powerful search site. At that time, most of the competing websites were competing to become portals, and they became comprehensive media sites such as Yahoo! to cater to the multiple interests and needs of users. The reason why it is focused on the search business is because Google thinks it is better than any other company in this area. It is because of the focus on the search engine that Google can provide users with better and better search results. Where is Yahoo now? From a strategic perspective, focusing on a single business or diversified business is a difficult choice for many companies. On the surface, we see Google as a great company that focuses on search engines and succeeds and see world-class companies like GE that have succeeded in many fields. However, to peel off the core of a diversified company, it is often seen that GE has achieved one of the best in many of its success areas. Those successful and diversified companies are essentially professionally successful. Concentration is the magic weapon for them to win.

The so-called platform is essentially a product or service that can attract suppliers and user groups

to form a multilateral market. In addition to Google, most of the hottest companies in China are platform companies. Baidu, Alibaba, and Tencent are all strong platforms for building platforms. 
Aside from these Internet giants who have worked for many years, those young and fast-growing companies are also good at building platforms. Nowadays, Didi is booming on the Internet-based car business. By providing passenger car service, the company has built a powerful trading platform for taxi drivers or private car owners and passengers [9]. Based on this, it has many users and related data. Profit from it. How can the platform succeed? The first is direct pain points. For example, Ali solves the problem of how hundreds of millions of small and medium-sized enterprises establish low-cost connections with customers [1]. The trick is to let operating vehicles and passengers find each other at the fastest speed and at the lowest cost. Direct pain points are the basic logic for the success of the platform. However, it is not enough just to reach the pain points [5]. Another condition given by Google is to grow up quickly. This is because today's competition is becoming increasingly fierce and any competitive advantage cannot be sustained. Therefore, you must grow up fast and keep your opponent's far behind. The previous conducts of Google can show that it is not easy for it to stand out with the other weapons in the business world when the search engine tool is neglected. The empire role of Google in shaping this conduct can be well identified. Also, the cooperation of this company with the other branches can help shape the way that the consumers know more about the products. It is responsible for the classification of content according to certain rules placed, the user wants to find what they want, essentially speaking, is a navigable site, with the increase of the amount of information, the search methods of navigation websites have obviously failed to meet the requirements of users of search engines. The subsequent generation of second-generation search engines represented by "keyword" search technology is an innovative search engine based on man-machine conversations, the user only needs to tell the search engine what he is looking for, and the search engine returns the results according to the user's request. "Keyword" search innovatively proposes page ranking technology and hyperlink analysis technology and presents the most important pages to users [5]. The representative product is Google. When Page was studying for a Ph.D., he found an interesting phenomenon. On the Internet, it was easy to link from one page to another, but finding backlinks was not easy. Page argued that it would be interesting to know backlinks. This is like the citations in academic papers. We always push our opinions out of others' arguments. Peggy built a model and experimented with 10 million pages. Then Peggy discovered that the complexity of the subject far exceeded the scope of the general doctoral thesis and invited bring to join. Finally, we jointly developed a PageRank system for rating web pages. Page has "organically" combined his surname with the one he is working on and named him "PageRank" (page rank) for his link rating system. In addition to considering the number of links on web pages, PageRank also considers the importance of linking web pages. In terms of method, it does not classify the literature itself according to the catalogue. Instead, it identifies "keywords" from the literature, and then establishes an inverted index, from Yahoo's user search method to Google's search method for human-machine dialogue, and to search. The concept of the engine achieved a qualitative leap forward [8]. The first-generation search engine technology could not solve the newly emerged problems, making users put demands on the search engine - making search more convenient, and Google satisfied the users through technological progress.

\section{Reflection on key learning from the module}

By learning this module, the strategic analysis of the corporate and enterprise in different angles has been learned effectively. For example, the demand factor in strategic development can be given well analysis in this case for Google thus creating a Google search engine. Google's search speed, generally can be completed within 0.5 seconds; comprehensive information. It can instantly grab 4.28 billion web pages, 880 million pictures and humanity, such as can be used with more than 100 languages and personalized search and so on, which has led to a proliferation of users, and even many people have a religious fanaticism. Its world-leading PageRank technology, keyword technology, and redundant file, filtering technology have made it difficult for other companies. Strong business 
capabilities make Google stand out, just like Business Weekly's evaluation of the Google brand [8]. Google is included in the latest Oxford dictionary as a verb, which confirms the fear of Google opponents. For many online users, Google is synonymous with search. Internet market research firm hit wise said that Google's share of the US search market rose slightly in April 2008, and Yahoo and Microsoft's market share continued to decline. In April, Google's share of the US Internet search market grew from 67.25\% in March to 67.9\%. Google's market share in the same period last year was $65.26 \%$ [5]. There are changing environments that the enterprise is confronted with in the dynamic international business development process. Therefore, it requires the enterprise to establish flexible strategic development points to develop in the long run.

\section{Conclusion}

To conclude, google did not like to provide all services free of charge, to win profits. If the service is free, then it means that the service is used to expand and mine users to sell ads. Google is currently involved in all aspects. Other products may be separate or as a complement to Google's efforts to create as many products as possible. As core business is reaching out to the crowd, Google expands online as much as possible. Once it attracts users, it can use its technology to maximize profitability opportunities.

\section{References}

[1] Cummings S, 2015. Strategic Management. Encyclopedia of Management. Vol.2, no.2, pp 22-28.

[2] Ethiraj S.K, Alfonso G, 2016. Replication in strategic management. Strategic Management Journal. Vol.37, no.1, pp 6-12.

[3] Fisher G, Michael L, 2016. Optimal distinctiveness: broadening the interface between institutional theory and strategic management. Strategic Management Journal. Vol.38, no.1, pp 7-14.

[4] Floyd S.W, Bill W, 2015. Middle management involvement in strategy and its association with strategic type: a research note. Strategic Management Journal. Vol.13, no.2, pp 16-23.

[5] Grundy T, 2014. Strategy as simplicity-rediscovering the essence of strategic management. Strategic Change. Vol.7, no.8, pp 5-14.

[6] Helfat C.E, 2018. Theory in strategic management. Strategic Management Journal. Vol.2, no.1, pp 22-29.

[7] Hagen B, Zucchella A, 2017. A taxonomy of strategic postures of international SMEs. European Management Review. Vol.14, no.3, pp 14-19.

[8] Rumelt R.P, Schendel D, 2014. Strategic management and economics. Strategic Management Journal. Vol.12, no.2, pp 19-22.

[9] Tallman S, 2017. Global strategic management. Handbook of Strategic Management. Vol.2, no.5, pp 26-33. 